Francisco Inácio Bastos

Rita de C Barradas Barata

Estela Maria Aquino

Maria do R D O Latorre

\section{Sexual behavior and} perceptions of the Brazilian population regarding HIV/AIDS

As rare as they are essential, surveys with national coverage are indispensable tools for formulating and monitoring public policies. In a partnership between the Brazilian Center for Analysis and Planning (Centro Brasileiro de Análise e Planejamento, CEBRAP) and the National STD/AIDS Program of the Brazilian Ministry of Health, a wide-ranging survey named "Sexual Behavior and Perceptions of the Brazilian Population regarding HIV/AIDS" was conducted in 2005, among a sample of 5,040 interviewees who were representative of the urban population of Brazil. This survey, like the previous one of the same name that was conducted in 1998, provided relevant information for delineating preventive actions.

Under the firm and inspirational leadership of the demographer Elza Berquó, this second survey renewed and expanded the proposition of the previous study to cover a vast range of essential questions relating to sexual and reproductive health. It also included topics like domestic violence and the abuse of alcohol and other psychoactive substances, which were explored in detail for the first time within the sphere of the present survey. It was backed by an advisory committee of specialists within the fields of statistics, epidemiology and sexual and reproductive health involving professors and researchers from the Universidade de São Paulo (USP), Universidade Estadual de Campinas (UNICAMP), Fundação Oswaldo Cruz (FIOCRUZ) and Fundação Getúlio Vargas São Paulo (FGV-SP).

The survey was preceded by a long period of debate and formulation of objectives, methodological strategies and instruments, starting in 2003, which took place by means of regular meetings and the establishment of an electronic debating list. It was succeeded by a new round of meetings and exchanges of electronic messages at the time of reviewing its database and performing integrated analysis of its results, throughout 2006-7.

The results from this arduous but rich and comprehensive work can be seen by the readers of the present supplement of the Revista de Saúde Pública, which was conceptualized by Professor Elza Berquó. The supplement brings together a significant set of articles relating to central aspects of the national survey.

In addition to the presentation of the supplement contributed by Dr. Pedro Chequer, the then coordinator of the National STD/AIDS Program, and an introduction written by Regina Barbosa and Elza Berquó, the supplement contains 12 original articles that were submitted to the same review procedures as adopted in compiling the regular issues of the journal.

Firstly, the sampling plan for the survey is described in detail. Next, the supplement presents articles that analyze the broader trends in the surveys conducted in 1998 and 2005 relating to sexual behavior among men and women, with subsequent emphasis on the use of condoms among the urban population of Brazil and on sexual initiation among young Brazilians (and the use of condoms at that time). This initial set of broader topics is concluded with an article on the opinions and attitudes of the Brazilian population regarding sexuality. 
In the second set of articles, questions that are essential in formulating public policies relating to HIV/AIDS are covered. These include the interrelated topics of the level of knowledge of HIV/AIDS and the perceptions of risks presented, stigma, discrimination and testing for HIV infection.

In the third set, there are articles dealing with specific topics relating to the signs and symptoms associated with sexually transmissible diseases; cofactors essential for dissemination of the AIDS virus that are important public health problems in themselves; patterns of alcohol and illegal drug consumption and their interrelationships with sexual and reproductive health; and the question of sexual violence perpetrated by intimate partners.

As readers will perceive, this is the most comprehensive publication within this field that has ever been undertaken in Brazil. It reveals the findings from a survey of national coverage that will certainly form the basis for policies that are more appropriate for the health needs of the Brazilian population. It also represents a successful response to the scientific and operational challenge of conducting surveys on sensitive questions in a country of continental dimensions, marked by striking regional and social inequalities. 